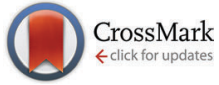

Cite this: J. Mater. Chem. B, 2016, 4, 6552

\title{
Photocrosslinkable polysaccharide hydrogel composites based on dextran or pullulan-amylose blends with cytokines for a human co-culture model of human osteoblasts and endothelial cells $\uparrow$
}

\author{
Ulrike Ritz, ${ }^{* a}$ Peter Kögler, ${ }^{b}$ Isabel Höfer, ${ }^{\text {bc }}$ Petra Frank, ${ }^{b}$ Sven Klees, ${ }^{b}$ \\ Sören Gebhard, ${ }^{\mathrm{b}}$ Christian Brendel, ${ }^{\mathrm{d}}$ Kerstin Kaufmann, ${ }^{\mathrm{e}}$ Alexander Hofmann, ${ }^{\mathrm{a}}$ \\ Pol Maria Rommens ${ }^{a}$ and Ulrich Jonas ${ }^{b}$
}

\begin{abstract}
Although a large body of research has been devoted to biomaterial development for bone tissue engineering and related medical disciplines in the last few years, novel and optimized materials especially for bone fractures of critical sizes demand continued development. In this respect, polysaccharide-based hydrogels demonstrate beneficial properties and fulfill the main requirements for a bone tissue scaffold as they are hydrophilic, biocompatible, and biodegradable. The aim of the present study was the development of a natural polysaccharide-based scaffold material that can integrate with the host tissue and support bone regeneration. For this purpose, we prepared and investigated two polymer hydrogel composites of photocrosslinkable derivatives of either pure dextran or a mixture of amylose and pullulan with varying composition. In order to increase their biological activity the swollen hydrogel matrices were compounded with stromal derived growth factor (SDF-1) and bone morphogenic protein (BMP-2). As skeletal development is known to depend on angiogenesis, these hydrogel systems were subjected to mono- and co-culture models of human primary osteoblasts (hOBs) with human endothelial cells (HUVEC - as precursors for blood vessel development). The effect of cytokines on hydrogel-dependent cell behavior was analyzed in the presence and absence of the growth factors SDF-1 and BMP-2. Both the employed cell types grew on all cytokine-modified hydrogel composites, which was assessed by optical microscopy and proliferation assays. Migration assays indicated enhanced HUVEC migration under the influence of SDF-1 and real-time PCR demonstrated an enhanced expression of cell-specific markers for growth factormodified hydrogels, thus demonstrating their functional bioactivity. Our results demonstrate the fundamental potential of such multi-component polysaccharide hydrogel composites as biomaterials for bone regeneration.
\end{abstract}

Received 14th March 2016,

Accepted 20th September 2016

DOI: $10.1039 / c 6 t b 00654 j$

www.rsc.org/MaterialsB

\section{Introduction}

Cell-based tissue engineering and regenerative medicine are established using mostly primary cells combined with artificial biomaterials and optionally with biological factors to improve or replace biological functions. Due to their critical medical and economic relevance for society these fields have been the focus of intense research in the last few decades. Best results have been

\footnotetext{
${ }^{a}$ University Medical Center of the Johannes Gutenberg University Mainz, Department of Orthopaedics and Traumatology, Biomatics Group Mainz, Germany.E-mail: ritz@uni-mainz.de

${ }^{b}$ Macromolecular Chemistry, University of Siegen, Germany

${ }^{c}$ TU Hamburg-Harburg, Umwelttechnik und Energiewirtschaft, Hamburg, Germany

${ }^{d}$ Children's Hospital, Harvard Medical School, Boston, USA

${ }^{e}$ University Health Network, Toronto, Canada

$\dagger$ Electronic supplementary information (ESI) available. See DOI: 10.1039/c6tb00654j
}

achieved by replacing or repairing parts of or whole tissues in the area of bone cartilage, ${ }^{1}$ skin, ${ }^{2}$ heart muscles, ${ }^{3}$ and vascular diseases. ${ }^{4}$ Demand for the development of tailored biomaterials suitable for regenerative medicine is high, as the target tissues involved require stringent conditions concerning mechanical and chemical characteristics. Often, a tailored degradation potential ${ }^{5}$ and a specific grade of porosity is implemented in the biomaterials to allow the infiltration of growing cells into the scaffold and formation of new tissue, eventually replacing the artificial support material. Furthermore, materials used in medical applications must be biocompatible, meaning "the ability of a material to locally trigger and guide non-fibrotic wound healing, reconstruction and tissue integration". 6

Hydrogels are soft materials composed of water-swollen networks (commonly based on cross-linked hydrophilic polymers), and have been employed in medical applications for years, such 
as wound dressing, ${ }^{7,8}$ contact lenses ${ }^{9-11}$ and drug delivery. ${ }^{12}$ Over the last few years, this material class has gained increasing attention for two-dimensional surface coatings as well as threedimensional scaffolds for tissue engineering and regenerative medicine, since the appropriately selected base components can fulfill all requirements needed for biomaterials in such applications. ${ }^{13}$ Depending on the material employed they are biocompatible, can be biodegradable, allow the diffusion of water and dissolved species (like nutrients and oxygen) through the hydrogel matrix, and promote cell growth of various cell types by closely mimicking the extracellular matrix (ECM). Importantly, their mechanical strength and stability can be finely tuned through different modifications ${ }^{14}$ to meet the requirements for use in tissue engineering applications. Moreover, the introduction of special functional groups in the hydrogel matrix enables specific binding and controlled release of proteins such as growth factors and cytokines. ${ }^{15}$

Cell-compatible hydrogels have been synthesized from a wide range of different materials including synthetic polymers such as polyethylene glycol (PEG) and polyacrylamide. Many natural polymers ranging from polysaccharides including alginate and hyaluronic acid to proteins such as fibrinogen, albumin and collagen among others have also been investigated. ${ }^{13}$ Covalent crosslinking of the hydrogel matrix is crucial to ensure the structure and stability of the film or scaffold to provide sufficient support for growing and proliferating cells, which is specifically important for implant coatings. To further provide mechanical integrity by the solid support, covalent attachment of the hydrogel layers is desired. Therefore, a variety of crosslinking strategies have been developed. Examples for chemical crosslinking include the use of carbodiimides or glutaraldehyde as crosslinking agents, or exposure to radiant energy to initiate the crosslinking reaction, e.g. by light induced photocrosslinking. ${ }^{16-18}$

One particularly promising area for hydrogels as scaffold materials is the field of bone tissue engineering for skeletal tissue repair, ${ }^{19}$ e.g. in fractures of critical sizes that do not heal under normal physiological circumstances. A central challenge in bone scaffolds for regenerative medicine is angiogenesis, the formation of new blood vessels. Many biological bone implants are rejected by the body due to insufficient connection to the surrounding tissue, and hence a lack of nutrients and oxygen. ${ }^{20}$ Several hydrogel materials support cell attachment and proliferation of a wide range of different cell types including endothelial cells, which are physiological relevant for neovascularisation and angiogenesis.

Our approach aimed to establish the basis for a threedimensional scaffold for pre-vascularized bone tissue made of photocrosslinked polysaccharide hydrogels and employing primary osteoblasts and endothelial cells. Previous work showed that these cell types mutually influence each other positively and enhance cell specific characteristics. ${ }^{21-23}$ As relevant polysaccharides, dextran and pullulan ${ }^{24,25}$ support cell growth and proliferation of endothelial cells, osteoblast and other cell types. ${ }^{26}$ Both polymers are promising candidates to be employed in hydrogel matrix systems for tissue engineering and regenerative medicine. Pullulan demonstrates good water solubility, ${ }^{27}$ making processing and modification steps under mild aqueous conditions possible. Furthermore, its hydrogels exhibit excellent mechanical stability with high water retention capacity. ${ }^{28}$ Similarly, dextran is a water soluble, nontoxic and biodegradable polysaccharide, which is able to form hydrogels with various other components. ${ }^{29}$ Both polysaccharides are generally considered biocompatible, ${ }^{30}$ yet not much research has been reported concerning their suitability as scaffold materials for bone tissue engineering in a three-dimensional co-culture model. In our previous study, we analyzed a dextran hydrogel system with BMP-2 for its biocompatibility and influence on osteoblasts and HUVECs ${ }^{24}$ for its potential use as a biomaterial for cell-based tissue engineering.

Based on this background, we investigate here a new photocrosslinked pullulan-amylose blend hydrogel in reference to the previously examined dextran system and further expand this study with SDF-1 as a new cytokine and by employing additional methods, like migration essays, monitoring the marker expression and influence on angiogenesis, etc.

\section{Experimental details}

\subsection{Polymer synthesis and hydrogel preparation}

Synthesis of 4-(2,3-epoxypropyloxy) benzophenone (EBP). The synthesis of EBP was performed according to the literature. ${ }^{31,32}$ Typically, $4 \mathrm{~g}$ (20.2 mmol) of 4-hydroxybenzophenone (Alfa Aesar, 98\% purity), $13.3 \mathrm{~g}$ (143.4 mmol) of epichlorohydrin (Alfa Aeser, $99 \%$ purity $)$ and $4.50 \mathrm{~g}(32.3 \mathrm{mmol})$ of anhydrous potassium carbonate powder were dissolved in butanone $(100 \mathrm{ml})$ and $0.8 \mathrm{ml}$ of polyethylene glycol 400 were added. The solution was stirred and heated for 20 hours at $80{ }^{\circ} \mathrm{C}$ and then refluxed for 4 hours at $120{ }^{\circ} \mathrm{C}$. After filtration, the inorganic residue was washed with butanone until the solution became colourless. The combined organic phase was concentrated by rotary evaporation and the residue was extracted with a chloroform/water mixture. Subsequently, the two phases were separated and the chloroform phase was dried over anhydrous calcium chloride. After drying, the yield of the crude product was $>85 \%$. The material was recrystallized from ethanol prior to further use.

${ }^{1} \mathrm{H}-\mathrm{NMR}\left(\mathrm{CDCl}_{3}, 400 \mathrm{MHz}\right): \delta(\mathrm{ppm}) 7.90-7.25,6.98(9 \mathrm{H}$, protons of aromatic ring); $4.33\left(1 \mathrm{H}, \mathrm{H} 1^{\prime}\right), 4.03(1 \mathrm{H}, \mathrm{H} 1), 3.80$ $(1 \mathrm{H}, \mathrm{H} 2), 3.40\left(1 \mathrm{H}, \mathrm{H} 3^{\prime}\right), 2.80(1 \mathrm{H}, \mathrm{H} 3)$ (protons of epoxy group).

EBP-coupling to the polysaccharides. To attach the benzophenone unit via an ether linkage to the polysaccharide backbone, typically $5 \mathrm{~g}$ (equivalent to $0.03 \mathrm{~mol}$ AGU (anhydroglucose units)) of dextran, amylose or pullulan were dissolved in approximately $350 \mathrm{ml}$ dry DMSO. $1.35 \mathrm{~g}(0.056 \mathrm{~mol})$ of sodium hydride (Sigma Aldrich) were added slowly. After stirring for $30 \mathrm{~min}, 1.7 \mathrm{~g}$ (0.007 mol) of EBP were added and the mixture was stirred at room temperature overnight. The reaction was terminated by careful addition of $100 \mathrm{ml}$ of distilled water and the product was precipitated in approximately $1 \mathrm{~L}$ of ice-cold acetone. The yields of the ether products were $70 \%$ for EBP-dextran (EBP-D), $60 \%$ for EBP-amylose (EBP-A) and 90\% for EBP-pullulan (EBP-P).

EBP-D: ${ }^{1} \mathrm{H}-\mathrm{NMR}\left(\mathrm{D}_{2} \mathrm{O}, 400 \mathrm{MHz}\right): \delta(\mathrm{ppm}) 7.90-6.48(9 \mathrm{H}$, arom. BP), 5.00, (1H, H1), 4.00 (1H, H6), 3.93 (1H, H5), 3.75 (2H, H6 , H3), 
3.55 (2H, H2, H4). DS-EBP (degree of substitution of benzophenone groups): 0.03 .

EBP-A: ${ }^{1} \mathrm{H}-\mathrm{NMR}$ (DMSO-d 6 , $\left.400 \mathrm{MHz}\right): \delta(\mathrm{ppm}) 7.75-7.10(9 \mathrm{H}$, arom. BP), 5.09, (1H, CH1), 4.17 (1H, H6), $3.66(1 \mathrm{H}, \mathrm{H} 5), 3.34(2 \mathrm{H}$, H6', H3), 3.24 (2H, H2, H4). DS-EBP: 0.01.

EBP-P: ${ }^{1} \mathrm{H}-\mathrm{NMR}\left(\mathrm{D}_{2} \mathrm{O}, 400 \mathrm{MHz}\right): \delta(\mathrm{ppm}) 7.75-7.11$ (9H, arom. BP), 5.01, 4.66 (1H, H1), $3.70\left(1 \mathrm{H}, \mathrm{H}^{\prime}\right), 3.62(1 \mathrm{H}, \mathrm{H} 5), 3.52(2 \mathrm{H}$, H6, H3), 3.34 (2H, H2, H4). DS-EBP: 0.05.

Carboxymethylation of the EBP-polysaccharides. For the subsequent carboxymethylation, typically $5 \mathrm{~g}$ of the benzophenonemodified polysaccharide were dissolved in $150 \mathrm{ml}$ distilled water followed by the addition of $10 \mathrm{~g}(0.1 \mathrm{~mol})$ of sodium chloroacetate (Acros Organics, 98\% purity). To initiate the reaction, $50 \mathrm{ml}$ of $8 \mathrm{M}$ aqueous sodium hydroxide solution were added and the reaction was carried out for 1 hour (only for pullulan 4 days) at $62{ }^{\circ} \mathrm{C}$. After cooling down for 10 minutes, the carboxymethylated polymers were precipitated into methanol and washed with a methanol-water-mixture $(9: 1)$. The yields were $60 \%$ for the dextran derivative EBP-CMD, 65\% amylose derivative EBP-CMA and $60 \%$ pullulan derivative EBP-CMP.

EBP-CMD: ${ }^{1} \mathrm{H}-\mathrm{NMR}\left(\mathrm{D}_{2} \mathrm{O}, 400 \mathrm{MHz}\right): \delta(\mathrm{ppm})$ 7.90-7.17 $(9 \mathrm{H}$, arom. BP), 5.22, 5.00, (1H, H1), 4.24, 4.19 (2H, MeCMH), $3.97(1 \mathrm{H}$, H6), 3.89 (1H, H5), 3.70 (2H, H6' , H3), 3.53 (2H, H2, H4). DS-CM (degree of substitution of carboxymethyl groups): 0.2.

EBP-CMA: ${ }^{1} \mathrm{H}-\mathrm{NMR}$ (DMSO-d 6 , $400 \mathrm{MHz}$ ): $\delta$ (ppm) 7.89-7.24 (9H, arom. BP), 5.63, 5.34, (1H, CH1), 4.36-4.12 (2H, МеСМH), 3.99 (1H, H6), 3.92 (1H, H5), 3.68 (2H, H6 $\left.{ }^{\prime}, \mathrm{H} 3\right), 3.59$ (2H, H2, H4). DS: $0.17-0.22$.

EBP-CMP: ${ }^{1} \mathrm{H}-\mathrm{NMR}$ (DMSO-d $\left.{ }_{6}, 400 \mathrm{MHz}\right): \delta(\mathrm{ppm}) 7.90-7.18(9 \mathrm{H}$, arom. BP), 5.64, 4.90 (1H, H1), 4.18 (2H, MeCMH), 4.07 (1H, H6'), 3.88 (1H, H5), 3.77 (2H, H6, H3), 3.56 (2H, H2, H4). DS: 0.21-0.29. GPC analysis, all in phosphate buffer: (more details provided in the $\mathrm{ESI} \dagger$ )

Dextran: $M_{\mathrm{n}}=7.44 \times 10^{3} \mathrm{~g} \mathrm{~mol}^{-1}, M_{\mathrm{w}}=4.51 \times 10^{4} \mathrm{~g} \mathrm{~mol}^{-1}$ EBP-CMD: $M_{\mathrm{n}}=3.23 \times 10^{3} \mathrm{~g} \mathrm{~mol}^{-1}, M_{\mathrm{w}}=1.06 \times 10^{4} \mathrm{~g} \mathrm{~mol}^{-1}$ Pullulan: $M_{\mathrm{n}}=5.10 \times 10^{4} \mathrm{~g} \mathrm{~mol}^{-1}, M_{\mathrm{w}}=1.98 \times 10^{5} \mathrm{~g} \mathrm{~mol}^{-1}$ EBP-CMP: $M_{\mathrm{n}}=7.00 \times 10^{3} \mathrm{~g} \mathrm{~mol}^{-1}, M_{\mathrm{w}}=3.95 \times 10^{4} \mathrm{~g} \mathrm{~mol}^{-1}$

Amylose: $M_{\mathrm{n}}=1.38 \times 10^{5} \mathrm{~g} \mathrm{~mol}^{-1}, M_{\mathrm{w}}=3.30 \times 10^{5} \mathrm{~g} \mathrm{~mol}^{-1}$ (the polymer was passed through a $0.45 \mu \mathrm{m}$ filter prior to recording GPC data to remove insoluble components)

EBP-CMA: $M_{\mathrm{n}}=7.11 \times 10^{3} \mathrm{~g} \mathrm{~mol}^{-1}, M_{\mathrm{w}}=8.47 \times 10^{4} \mathrm{~g} \mathrm{~mol}^{-1}$

Synthesis of the adhesion polymer P(85NIPAAm-5MAA10BPAAm). The adhesion polymer, here abbreviated P(85NIPAAm5MAA-10BPAAm), was obtained by free radical copolymerization of $85 \mathrm{~mol} \% \mathrm{~N}$-isopropylacrylamide (NIPAAm, recrystallized from $n$-hexane), 5 mol\% methacrylic acid (MAA) (destabilised and purified over an $\mathrm{Al}_{2} \mathrm{O}_{3}$ column) and $10 \mathrm{~mol} \% \mathrm{~N}$-(4-benzoylphenyl)acrylamide (BPAAm) following the procedure described by Beines et al. ${ }^{33}$ The molar mass of $M_{\mathrm{n}}=5.0 \times 10^{4} \mathrm{~g} \mathrm{~mol}^{-1}$ and $M_{\mathrm{w}}=1.4 \times 10^{5} \mathrm{~g} \mathrm{~mol}^{-1}$ was measured by GPC (Agilent 1260 infinity) on a GRAM LinM column in dimethylacetamide and $0.1 \% \mathrm{LiBr}$ at $60{ }^{\circ} \mathrm{C}$ (injection volume/flow rate, $\left.20 \mu \mathrm{l} / 1 \mathrm{ml} \mathrm{min}{ }^{-1}\right)$. ${ }^{1} \mathrm{H}-\mathrm{NMR}\left(\mathrm{CDCl}_{3}, 400 \mathrm{MHz}\right)$ : $\delta=1.27$ (s, $6 \mathrm{H}, 2 \times \mathrm{CH}_{3}$ ), 1.48-2.40 (backbone), 3.80-4.10 (br. s, $1 \mathrm{H}$, $\left.\mathrm{CH}\left(\mathrm{CH}_{3}\right)_{2}\right), 7.36-7.90$ (BPAAm). BPAAm was synthesized from 4-aminobenzophenone and acryloyl chloride with triethylamine as base according to Jia et al. $^{34}$
Preparation of the hydrogel layers in 24-well plates. Polystyrene 24-well plates were rinsed several times with ethanol, dried and coated with the P(85NIPAM-5MAA-10BPAAm) adhesion polymer. Briefly, $60 \mu \mathrm{l}$ of a $0.25 \%(\mathrm{w} / \mathrm{w})$ polymer solution in $70: 30(\mathrm{v} / \mathrm{v})$ ethanol : water were applied to each well of a 24 well TCPS plate. The solvent was evaporated at room temperature while shaking gently to ensure even film formation. After drying, the samples were irradiated for one hour at $365 \mathrm{~nm}\left(17 \mathrm{~J} \mathrm{~cm}^{-2}\right)$ under nitrogen to induce crosslinking (UVP CL-1000 Ultraviolet Crosslinker). Subsequently, aqueous solutions of EBP-CMA, EBP-CMP, EBP-CMA and the respective mixtures for the composites were prepared. An aqueous solution of gelatin was added dropwise to the polymer solution while stirring followed by the addition of benzophenone-modified silica particles ${ }^{35}$ to a final concentration of $10 \mathrm{w} \%$ with respect to the polymer. The mechanical properties including swelling behaviour, critical temperature and SPR/OWS experiments have been described for an analogous hydrogel system by van den Brom et al. ${ }^{35} 300 \mu \mathrm{l}$ of the respective final mixtures were added into each well and dried at $37{ }^{\circ} \mathrm{C}$ for $18 \mathrm{~h}$. After drying, the samples were irradiated for one hour at $254 \mathrm{~nm}$ (10.4 $\mathrm{J} \mathrm{cm}^{-2}$ ) under nitrogen. To investigate the porous superstructure of the hydrogels cryo-SEM measurements were carried out. Therefore, a part of dried bulk hydrogels was crosslinked, swollen in buffer, and frozen in liquid nitrogen. After the water was sublimed the hydrogels were coated with platinum and observed using a cryo-SEM under high vacuum (Fig. S2, ESI $\dagger$ ). The measurements show a macroporous structure in the micrometer range which is consistent with the literature for various dextran based hydrogel systems. ${ }^{36}$ These results clearly indicate that macropores exist in the hydrogel matrix. One has to keep in mind that the macropores are not expected to represent rigid pores in the swollen state, but rather resemble a flexible network.

Binding and release of cytokines. Growth factors (300 ng per well) were entrapped in the hydrogels in presence and absence of 1-ethyl-3-(3-dimethylaminopropyl)carbodiimide hydrochloride (EDC $\mathrm{HCl}$, Applichem, Darmstadt, Germany) and $N$-hydroxysuccinimide (NHS, Sigma Aldrich) according to the following protocol. First, the hydrogels were washed three times with $1 \times$ phosphate buffered saline PBS (Dulbecco, Invitrogen). Subsequently, they were incubated in PBS for 30 minutes at room temperature to allow swelling and equilibration of the gels. A $0.4 \mathrm{M}$ aqueous solution of EDC $\mathrm{HCl}$ was mixed $1: 1(\mathrm{v} / \mathrm{v})$ with a $0.1 \mathrm{M}$ aqueous solution of NHS, added directly to the hydrogels ( $500 \mu \mathrm{l} / 24$ wells) and incubated for $10 \mathrm{~min}$ at room temperature before the respective growth factors were added BMP-2 (stock solution: $10 \mu \mathrm{g} \mathrm{ml}^{-1}$ in PBS) and SDF-1 (stock solution: $100 \mu \mathrm{g} \mathrm{ml}^{-1}$ in PBS), (Miltenyi, Bergisch Gladbach, Germany). After an incubation period of 1 hour and a short rinsing step with PBS, the modified gels were used in further experiments. The release of the entrapped growth factors was measured employing specific ELISA-tests (abcam, Cambridge, Great Britain) after 1, 2, 3, 4, 8, 24 and 30 hours. For a clearer presentation of the release data, the measured concentrations of the growth factors after 8, 24 and 30 hours were divided by the time intervals between release measurements (difference in hours and converted to release/hour). All experiments were performed in triplicate and repeated three times. 
In vitro cytotoxicity assessment of hydrogels. The in vitro cytotoxicity was analysed employing the MTT ([3-(4,5-dimethylthiazol-2-yl)-(2,5-diphenyltetrazolium bromide)]) assay analogous to ISO 10993-5. Mouse L929 cells (20000 cells per well) were seeded in a 96 well tissue culture polystyrene (TCPS) plate for 24 hours before they were exposed to $100 \mu \mathrm{l}$ fluid extracts from the hydrogels after incubation for 24 hours. One group of three dextran/amylose (50:50) and pullulan-amylose (50:50) hydrogels, respectively, was washed with PBS three times before culture media were added and incubated for 24 hours. $100 \mu \mathrm{l}$ of this extract were added to L929 cells in the 96 well plate. After an incubation time of 24 hours, the MTT assay was performed according to ISO 10993-5. The colorimetric readout was performed at a wavelength of $570 \mathrm{~nm}$ (reference wavelength $650 \mathrm{~nm}$ ). Another group was incubated with cell culture media without PBS washing steps and treated as the previous group. Polyurethane membranes stabilized with organic zinc derivatives ZDEC (zinc diethyl dithiocarbamate) and ZDBC (zinc dibutyl dithiocarbamate) (Food and Drug Safety Center, Hatano Research Institute, Ochiai 729-5, Hadanoshi, Kanagawa 257, Japan) were used as positive controls. These controls induce a reproducible cytotoxic reaction.

\subsection{Cell experiments}

Primary human osteoblasts (hOBs). Osteoblast cultures were prepared from cancellous bone fragments taken from patients undergoing orthopedic and trauma surgery. Informed consent was obtained from all patients, and the local ethical committee approved the investigations [No: RLP 837.046.03(3708)]. Isolation was performed as described previously. ${ }^{37}$ In short, the fragments were digested with collagenase type IV (Sigma-Aldrich), washed with PBS to remove blood and fat residues and the clean bone fragments were placed in 6-well plates (Becton-Dickinson, Heidelberg) and cultured in DMEM/F12 (Biochrom, Germany) supplemented with $10 \%$ heat inactivated fetal calf serum (PAA Lab, Austria), $100 \mathrm{U} \mathrm{ml}^{-1}$ penicillin and $100 \mathrm{mg} \mathrm{ml}^{-1}$ streptomycin sulfate at $37{ }^{\circ} \mathrm{C}, 5 \% \mathrm{CO}_{2}$. The specific phenotype was assessed by the expression of alkaline phosphatase visualized by using 5-bromo-4-chloro-3indolyl-phosphate/nitro-blue-tetrazolium as a substrate (SigmaAldrich) and mineralization of the extracellular matrix using Alizarin Red-S (Sigma-Aldrich) (ESI, $\dagger$ Fig. S1) after cultivation in differentiation media (DMEM/F12, 10\%FCS, $100 \mathrm{U} \mathrm{ml}^{-1}$ penicillin and $100 \mathrm{mg} \mathrm{ml}^{-1}$ streptomycin sulfate containing $200 \mu \mathrm{g} \mathrm{ml}^{-1}$ ascorbate, $10^{-8} \mathrm{M}$ dexamethasone and $50 \mu \mathrm{g} \mathrm{ml} \mathrm{m}^{-1} \beta$-glycerophosphate) for four weeks. For cell culture experiments, undifferentiated osteoblasts in passages 2-4 were used.

Human umbilical vein endothelial cells (HUVECs). HUVECs were purchased from PromoCell GmbH (Heidelberg, Germany) and cultured in EBM-2 (endothelial cell growth medium, Lonza, Walkersville, USA) supplemented with the provided kit, as well as with $100 \mathrm{U} \mathrm{ml}^{-1}$ penicillin, and $100 \mathrm{mg} \mathrm{ml}^{-1}$ streptomycin sulfate, in a humidified atmosphere $\left(5 \% \mathrm{CO}_{2}, 37{ }^{\circ} \mathrm{C}\right)$. Media were changed twice a week. Cells up to passage eight were used for experiments.

Lentiviral vector particle production and transduction of fibroblasts. The eGFP or cherry protein encoding lentiviral vector pHR'-SEW was used to prepare vector supernatants by transfection of $293 \mathrm{~T}$ cells as previously described. ${ }^{38}$ For gene transfer, 15000 human osteoblasts (hOBs) or HUVECs were seeded into 24-well tissue culture plates (Greiner, Frickenhausen, Germany) in $500 \mu \mathrm{l}$ media supplemented with $5 \mu \mathrm{g} \mathrm{ml} \mathrm{m}^{-1}$ protamine sulfate. Two rounds of transduction on day 1 and 3 were performed at a cumulative multiplicity of infection (MOI) of $\sim 100$ to achieve $>98 \%$ gene marking. Transduction efficiency was confirmed by fluorescence microscopy (Wilovert AFL30, Hundt GmbH, Wetzlar, Germany) and flow cytometry FACSCalibur (BD Biosciences, San Jose, USA) using the CellQuestPro Software (BD Biosciences, San Jose, USA).

Mono- and co-cultures on polysaccharide hydrogels. Before cell seeding, the hydrogel films in the 24 well plates were washed three times with sterile PBS (Dulbecco, Invitrogen) to remove potential chemical residues that remained from hydrogel synthesis. After the last washing step, the hydrogels were incubated for at least 30 minutes with PBS at room temperature to allow swelling equilibration. The PBS was removed and the cells were seeded in monoculture (100000 cells) or co-culture from HUVECs and hOBs (50000 cells each). The incubated hydrogels were cultured for four weeks with media change twice a week. Microscopy analyses were performed every two days and the photos of the hydrogels were taken for data collection using the EVOS Cell Imaging System (Life Technologies, Darmstadt, Germany).

Proliferation assays. Cell viability and proliferation on the hydrogel films were measured using the semi-quantitative colorimetric alamarBlue assay (Invitrogen, Karlsruhe, Germany). Cells were seeded on the hydrogels as described above and after 24 hours of incubation, the medium was removed and replaced by a culture medium solution containing $10 \%$ alamarBlue. The hydrogels with cells were further incubated for $4 \mathrm{~h}$ at $37^{\circ} \mathrm{C}$. Aliquots of $100 \mu \mathrm{l}$ were transferred into the wells of 96 well plates and the fluorescence was measured using a fluorescence reader (Glomax, Promega, Mannheim, Germany) at $590 \mathrm{~nm}$ (emission wavelength 580-610, excitation wavelength 540-570 nm). The assay was performed once every 24 hours over a time period of five days. The cell proliferation correlates with the fluorescence intensity. As a negative control, alamarBlue was added to the hydrogels with cell growth medium without cells.

Migration assays. For migration assays, cell culture inserts with a pore size of $8 \mu \mathrm{m}$ for a 24 well format were used (BD Biosciences). 100000 lentiviral transduced cells were seeded in the culture insert placed in a 24 well plate modified with hydrogel films. Migration of cells through the insert pores was measured using a fluorescence reader (Glomax, emission wavelength $490 \mathrm{~nm}$, excitation wavelength $510-570 \mathrm{~nm}$ ) after two, three and six days and correlated to a standard curve and compared to a negative control (hydrogels without growth factor modification).

Gene expression analyses by real-time PCR. The total RNA was extracted using TRIzol-chloroform (Invitrogen, Karlsruhe, Germany) and purified employing an RNeasy Micro Kit (Qiagen $\mathrm{GmbH}$, Hilden, Germany) according to the manufacturer's instructions. Quantitative real-time PCR was performed to evaluate the stability of the hOB and HUVEC phenotypes by analyzing the expression of various differentiation markers using the 7300 ABI sequence detection system (Applied Biosystems). 
Validated QuantiTech Primer. Assay Kits were used for the following genes: ALP (QT00012957), CD31 (QT00081172), osteopontin (QT01008798), von-Willebrand-factor (QT00051975), Cbfa1/ Runx2 (QT00020517), and 18S RNA housekeeping gene as the control (QT00199367). Real-time PCR reactions were carried out using $100 \mathrm{ng}$ cDNA samples, 1XQuantiTech primers, and 1XQuantiTech SYBR-Green PCR master mix in a total volume of $20 \mu \mathrm{l}$ using the suggested thermal profiles. The data were analyzed using SDS 2.1 software (Applied Biosystems) and quantified using the $2 \mathrm{dCt}$ method. Reverse transcription was performed using $2 \mathrm{mg}$ of RNA from each sample, random primers (Promega) and superscript III reverse transcriptase (Invitrogen).

Statistical analyses. All experiments and measurements were performed at least in triplicate and represented as bar graphs with medians and standard deviations (cytotoxicity, cytokine release). For statistical analysis (proliferation, migration, PCR), the IBM SPSS Statistics software version 23 was used. The data distribution was defined by medians \pm quartiles. The measurement values were normalized to the median of the control group (control median) and presented as \%-values related to the control group in bars or box-plots.

For multiple comparisons, the paired non-parametric Wilcoxontest was performed, as the Kolmogorov-Smirnov test did not demonstrate a normal data distribution. Differences were considered to be statistically significant for $p<0.05$.

\section{Results and discussion}

\subsection{Hydrogel systems}

In the present study, we investigated the cellular response of endothelial cells and osteoblast cells towards two-dimensional hydrogel systems based on photocrosslinkable polysaccharide composites. The hydrogel components comprised carboxymethylated polysaccharides derived from dextran (Dex) or from pullulan (Pull) blended with amylose (Amy). Amylose was added to the pullulan gel matrix as an enzyme-digestible component ${ }^{39}$ to provide increased gel porosity and nutrition for cells during attachment, growth and proliferation phases. Fast degradation (within hours) of the hydrogel films under cell culture conditions was observed for pure photocrosslinked amylose systems, corroborating their digestible nature. Simultaneously, enrichment with gelatin was employed to provide nutrition and enhance cell-hydrogel interaction. ${ }^{24}$ In the pullulan-amylose composites, comparison between gelatin-enriched with gelatin-free hydrogels allowed to distinguish the effect of amylose from the effect of gelatin on the cellular response (see, for example, Fig. 4).

To improve the mechanical stability in the hydrogel layers benzophenone-functionalized silica nanoparticles $\left(\mathrm{SiO}_{2} \mathrm{NP}\right)$ were incorporated in the gel matrix. Through the BP-functionalities on the particle surface, covalent anchorage within the polymer network was achieved via multiple attachment points. This "supercrosslinking" effect of the functionalized nanoparticles leads to a substantial increase in mechanical robustness with a reduced swelling ratio (as previously investigated in detail for another hydrogel layer system ${ }^{35}$ ), which is also directly observable when handling the hydrogel films, as nanoparticle-free gels are extremely soft and easily punctured by a pipette tip.

In order to ensure firm attachment to the substrate material (TCPS dish) and the formation of a uniform layer of hydrogel composites, a thin layer of an adhesion polymer was first applied to the TCPS surface. This terpolymer consisting of NIPAAM, BPAAm and MAA was synthesized via free radical polymerization. It was subsequently dissolved in an ethanol/water mixture at 0.25 weight $\%$ and applied to the substrate material as a thin film. Even spreading of the film during drying was ensured through placement on a shaker. After evaporation of the solvent a clear polymeric film was obtained and crosslinking with simultaneous attachment to the substrate was induced by irradiation at $356 \mathrm{~nm}$ $\left(17 \mathrm{~J} \mathrm{~cm}^{-2}\right)$ for one hour in a nitrogen atmosphere. Subsequently, aqueous solutions containing the composite systems dextran/ gelatin/ $/ \mathrm{SiO}_{2} \mathrm{NP}$ or pullulan/amylose/gelatin/ $/ \mathrm{SiO}_{2} \mathrm{NP}$ were applied to the wells. The solvent was evaporated at $37{ }^{\circ} \mathrm{C}$ in the dark. After removal of the solvent, attachment to the substrate as well as crosslinking of the hydrogels was achieved through UV-exposure at $254 \mathrm{~nm}\left(10.4 \mathrm{~J} \mathrm{~cm}^{-2}\right)$ for one hour under nitrogen atmosphere.

On these different hydrogel composites, mono- and co-culture models were tested for human osteoblasts (hOBs) and endothelial cells (HUVECs) in order to assess the suitability of these polysaccharide materials as growth supports in bone replacement applications.

Hydrogels with pure amylose, although stable in water or PBS, demonstrated a low stability and completely degraded within a few hours after cell seeding, for which we speculate that enzymatic degradation might be responsible for the instability of pure amylose hydrogels. In contrast, pure pullulan hydrogels showed a hard cell repellent structure even after swelling. On these hydrogels, no cell attachment and growth was detected. As these single polysaccharide systems did not demonstrate enhanced cell support properties they were not further investigated. On the other hand, pure dextran hydrogels showed slightly better stability with minor cell attachment and growth as already demonstrated by our former study. ${ }^{24}$ In order to investigate the combined properties of amylose (fast degradation as nutrition supply) and pullulan (providing a stable hydrogel support) several polymer blends of both polysaccharides were prepared. The two polymers were mixed at ratios of 25/75; 50/50; and 75/25 (w/w), respectively. As mentioned above, all pullulan-amylose blends as well as the pure dextran system were further modified with $10 \mathrm{w} \%$ gelatin and $10 \mathrm{w} \%$ silica particles to enhance cell growth and increase the mechanical stability of the gels. Brom et $a l^{35}$ described the synthesis of modified silica nanoparticles, their incorporation in poly( $N$-isopropylacrylamide)-based (PNIPAAm) hydrogels and their influence on swelling behavior and stability. They demonstrated an even distribution of nanoparticles in the gels and showed that the NPs served as a supercrosslinking agent, providing a more rigid structure. In our former study, we tested various concentrations of silica particles in dextran gels ${ }^{24}$ (data not shown) and experimentally found that a concentration of $10 \%$ silica nanoparticles demonstrated the best ratio between stability, swelling ratio and cell growth. These results were transferred to the amylose-pullulan hydrogels here and the cellular analyses 

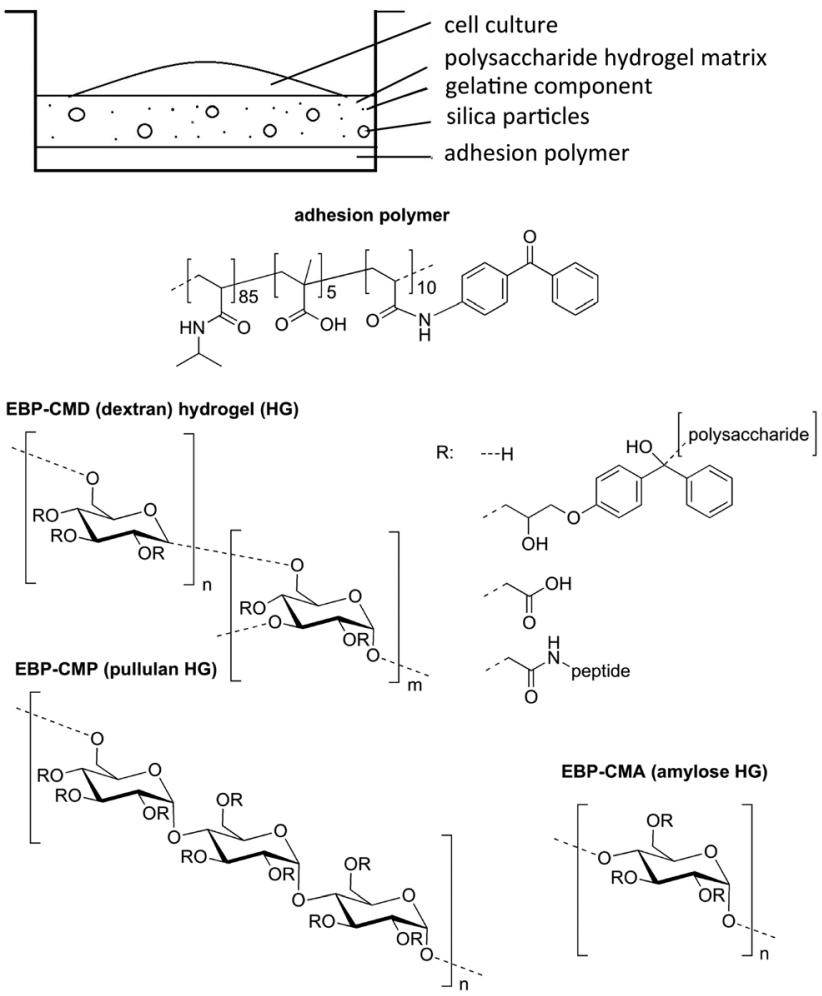

Fig. 1 Schematic of the hydrogel layer structure and the corresponding polymers used in this cell culture study.

suggest that the mechanical effect of silica nanoparticles on dextran and amylose-pullulan hydrogels is comparable to the PNIPAAm system. A detailed assessment of the exact influence of silica particles on these models has to be performed in a further study (Fig. 1).

\subsection{Cytotoxicity/MTT assays}

Cytotoxicity assays were performed to demonstrate the biocompatibility and non-toxicity of polysaccharide hydrogels used in this study analogous to ISO10993-5. L929 mouse fibroblasts were incubated in hydrogel extracts containing dextran or three different variations of pullulan and amylose mixtures $(25 / 75 ; 50 / 50$; and $75 / 25 \mathrm{w} / \mathrm{w} \%$ ). No cytotoxic effects were observed, as is evident from the high cell viability ranging from $93-126 \%$ (Fig. 2). A cell viability of $100 \%$ corresponds to cells growing on tissue culture treated polystyrene substrates. Cell viabilities $>70 \%$ indicate no cytotoxic effects, whereas cell viability between 0 and $40 \%$ represents high cytotoxicity, which is represented by the positive controls (ZDEC and ZDBC as polyurethane matrices stabilized with organic zinc, see Experimental details).

These results demonstrate high cell compatibility of the polysaccharide hydrogels used. Only little data are available concerning the biocompatibility and cytotoxicity of the specific carboxymethylated and benzophenone-modified polysaccharides used in this study and their potential as materials for bone tissue engineering. ${ }^{26,28-30,39-41}$ In addition, while few groups have already demonstrated the insertion of amylose in hydrogel preparations, ${ }^{42-44}$ no data are available on amylose as a

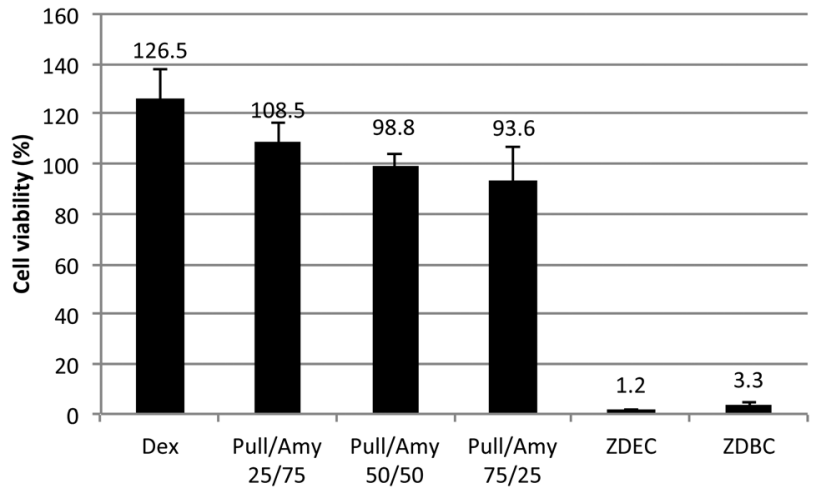

Fig. 2 Cytotoxicity assay (MTT) demonstrating cell growth compared to the cell culture treated polystyrene (Dex: dextran-based hydrogel composite, Pull/Amy: pullulan-amylose-based hydrogel composite, ZDEC: zinc diethyl dithiocarbamate-releasing polyurethane, ZDBC: zinc dibutyl dithiocarbamate-releasing polyurethane).

component in hydrogels for cell growth. Mixing of various polysaccharides to generate blends or composites is a common approach to combine desirable effects of the individual polysaccharides. For example, mixtures of pullulan with other biopolymers, e.g. collagen, ${ }^{4-47}$ were demonstrated to be biocompatible. Cytotoxicity tests for the adhesion polymer based on NIPAAM, MAA and BPAAm were performed in an independent study and showed low cell adhesion with no cytotoxic effects. ${ }^{48}$

It is of tremendous importance to ensure transferability of the developed methodology to different substrate materials. For example, titanium is routinely used in bone replacement applications due to its outstanding mechanical properties. A composite material consisting of titanium, an adhesion polymer and a polysaccharide hydrogel modified with cells and/or cytokines could enhance fracture healing. The prerequisite for such a material is the demonstrated cell compatibility of the adhesion polymer and polysaccharide hydrogel.

\subsection{Growth factor release}

In order to assess the effect of hydrogel-associated cytokines on cell growth and differentiation, $300 \mathrm{ng}$ per well of the growth factors SDF-1 and BMP-2, respectively, were used for the entrapment procedure (see Experimental details) of the various hydrogels plated in 24 well plates. The release rate was measured in the supernatant by a specific ELISA-test. In all tested hydrogels, the amount of cytokines released was comparable, and therefore the results are averaged in Fig. 3.

Cytokine concentrations in the supernatant of the hydrogels were measured after adsorption of the growth factors in the gels with and without addition of linker molecules (EDC \& NHS). Without linker molecules, 95\% of the growth factors were released within eight hours after binding. With EDC/NHS linking, approximately $90 \%$ of the cytokines were released after 30 hours (Fig. 3A). The remaining $10 \%$ were either released at concentrations below the detection limit or covalently immobilized in the hydrogel matrix. This might indicate that EDC and NHS in combination alter the solvation characteristics of the hydrogels, hence causing a slower release of cytokines from the gel matrix. 
A

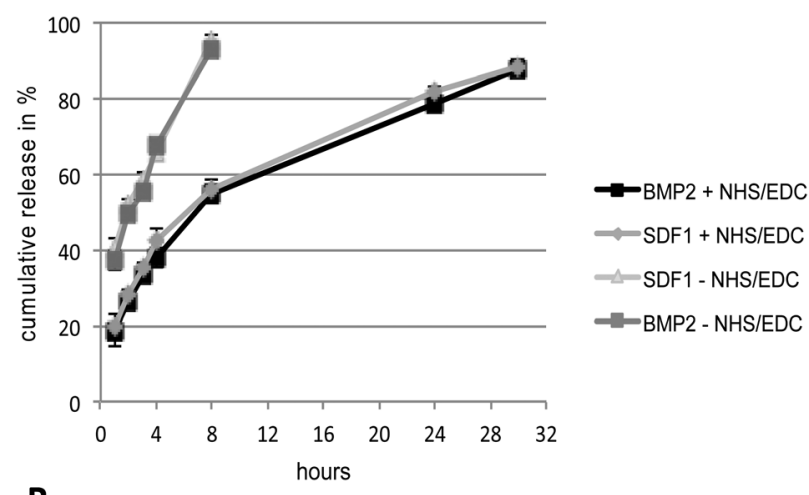

B

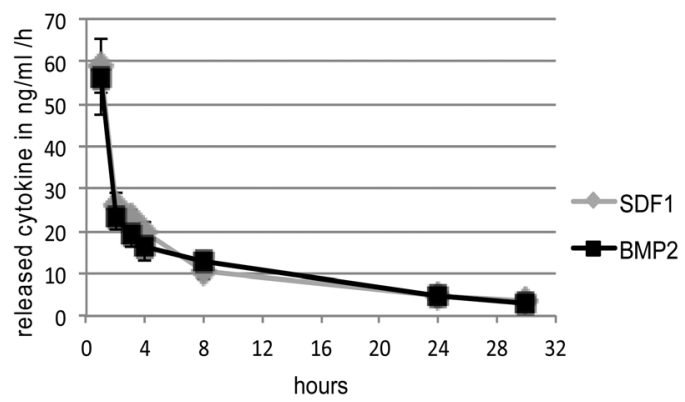

Fig. 3 (A) ELISA assay analysis of the cumulative release of SDF1 and BMP2 for hydrogels treated with and without linker molecules EDC and NHS over a period of 30 hours. (B) The total amount of cytokines (treated with $\mathrm{EDC} / \mathrm{NHS}$ ) released from hydrogels over a period of 30 hours.

However, further experiments are required to confirm this hypothesis.

All hydrogels that were treated with cytokines in the presence of EDC/NHS show a high initial release in the first hour (59.2 ng SDF-1 per $\mathrm{h}$ and $56.4 \mathrm{ng}$ BMP-2 per $\mathrm{h}$ ), which corresponds to approximately one fifth of the total amount of cytokines applied. This high initial release is followed by reduced release rates of 25.9-19.5 ng SDF-1 per $\mathrm{h}$ and 23-16.1 ng BMP-2 per h up to 8 hours, respectively. From 8 to 30 hours, the rate declines further to 10.5-3.5 $\mathrm{ng}$ SDF-1 per $\mathrm{h}$ and 12.8-2.9 $\mathrm{ng}$ BMP-2 per h; after that no cytokines can be detected in the supernatant. The total amount of cytokines released is $88.5 \%$ for SDF- 1 and $87.9 \%$ for BMP-2 (Fig. 3B).

BMP-2 was chosen since its role in osteogenesis is well defined ${ }^{49}$ and its functional activity can readily be assessed by determination of the enhancement of osteoblast marker expression by real-time PCR. BMP-2 exerts inductive properties on osteoblasts as well as on mesenchymal stem cells (MSCs). It enhances osteoblast differentiation, mineralization as well as extracellular matrix production via at least two pathways, one mediated by SMAD molecules and the other by p38/MAPK (mitogen activated protein kinase). ${ }^{49}$ SDF-1 on the other hand is known to induce angiogenesis by homing CD34+-cells and MSC via CXCR4. ${ }^{50}$

After incubation of the hydrogels with the respective growth factors in the presence of EDC/NHS we could demonstrate the cytokine release over 30 hours. This is in line with the available literature and was shown to be sufficient for an enhanced healing effect. ${ }^{51}$ Both cytokines show a short half-life in blood (SDF-1 approx. $25 \mathrm{~min} ;{ }^{52}$ BMP-2 7-16 $\mathrm{min}^{53}$ ). One therapeutic application of these hydrogels might be a carrier system for cytokines potentially as a composite material in combination with a resorbable bone replacement material. The release kinetics demonstrated by our hydrogels with initially high concentrations and the following lower release over 30 hours will be adequate for chemotactic activation of stem cells and to enhance osteoblast activation. $^{54}$

\subsection{Cell growth}

In order to monitor the influence of the various polysaccharide hydrogels on different cell types, the cell morphology, cell clustering and cell-cell interaction were analyzed microscopically over a time span of maximum four weeks. In the absence of growth factors, cell growth was observed for osteoblasts (hOBs, transduced with green fluorescent protein) in monocultures as well as hOB/HUVEC co-cultures. In line with previous studies ${ }^{24,37}$ no cell growth was observed in HUVEC (transduced with cherry red protein) monocultures. After incubation of the hydrogels with the respective growth factors SDF-1 and BMP-2, cell growth occurred in the co-cultures as well as in the monocultures of both cell types, highlighting the retained function of growth factors after entrapment and release from the hydrogel matrix. Both monocultures grew preferentially along the buckling structure of the hydrogels, indicating a topographical influence on cell alignment. Nevertheless, the following differences could be detected concerning the mode and arrangement in co-cultures:

On pullulan-amylose gels with and without additional gelatin and $\mathrm{SiO}_{2} \mathrm{NPs}$ the co-cultures formed spheroid-like structures and began to form very small sprouts (Fig. 4, arrows). This was observed in both types of pullulan-amylose gels with and without additional gelatin and $\mathrm{SiO}_{2} \mathrm{NPs}$. The spheroids were formed by both cell types, with osteoblasts (green) being rather in the center and endothelial cells (red) apparently surrounding the osteoblasts; this effect is more enhanced in the gels without silica particles/gelatin. In contrast, the growth of co-cultures on dextran gels was comparable to the growth of the monocultures and followed the topographic structure of the gels (Fig. 4D, yellow, indicating both cell types growing on the very spot). In a former study, we could already demonstrate that cell growth on dextran gels with $\mathrm{SiO}_{2} \mathrm{NPs}$ and gelatin particles is enhanced, as the microscopic analyses with these gels show. ${ }^{24}$

Fig. 4 shows cell growth with mono- and co-cultures after addition and release of both growth factors. Importantly, cell growth in monocultures is comparable between all types of hydrogels employed but cell growth patterns in co-cultures vary between different hydrogel systems. In particular, on dextranbased hydrogels the co-cultures grow in an adhesive manner along wrinkles in the hydrogel structure. This is indicated by the spread morphology of the cultured cells, indicating a cell supportive base material. On the contrary, on pullulan-amylose gels cells form spheroid-like clusters, indicating a less cell adhesive hydrogel base. SEM analyses (see ESI, $\uparrow$ Fig. S2) demonstrated macropores in the dried state under SEM conditions in the dextran hydrogels, which potentially augment cell growth along the 
dextran hydrogels with silica/gelatine particles

A

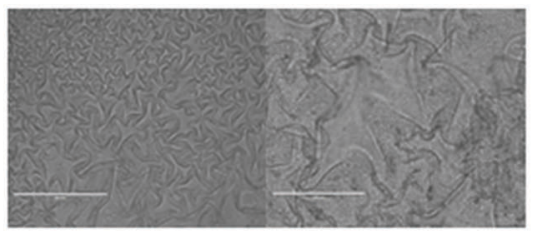

B

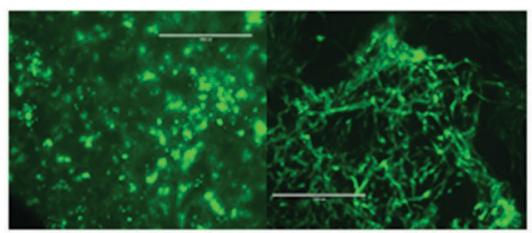

C

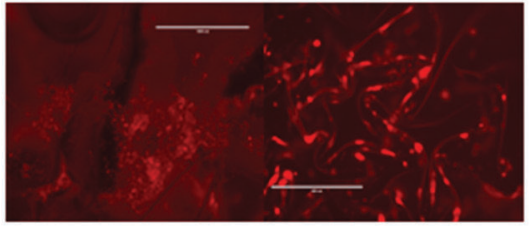

D

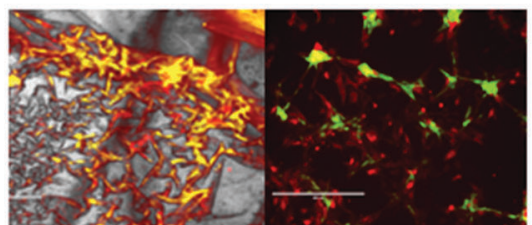

pullulan/amylose hydrogels without silica/gelatine particles
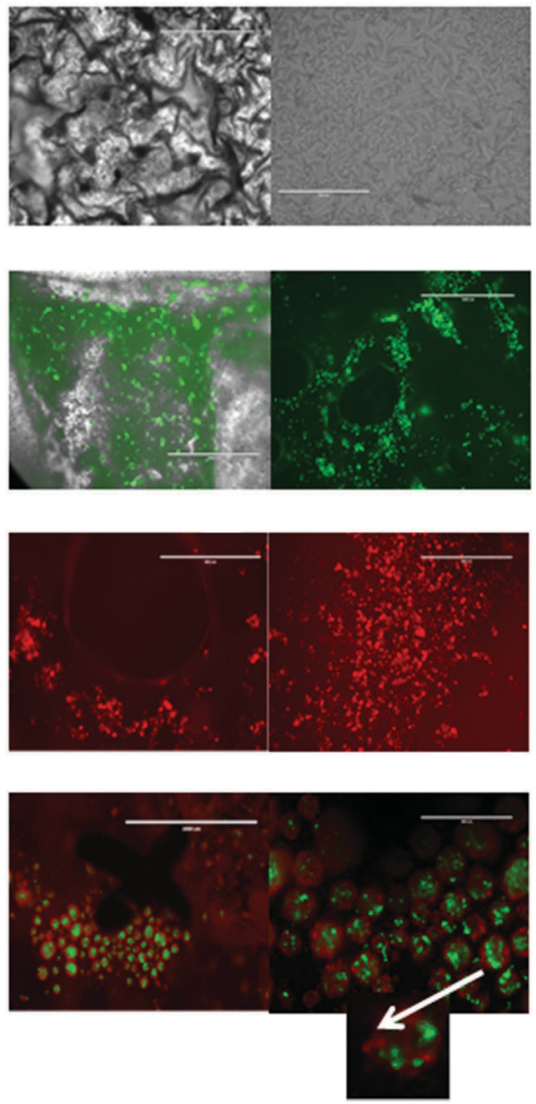

pullulan/amylose hydrogels with silica/gelatine particles
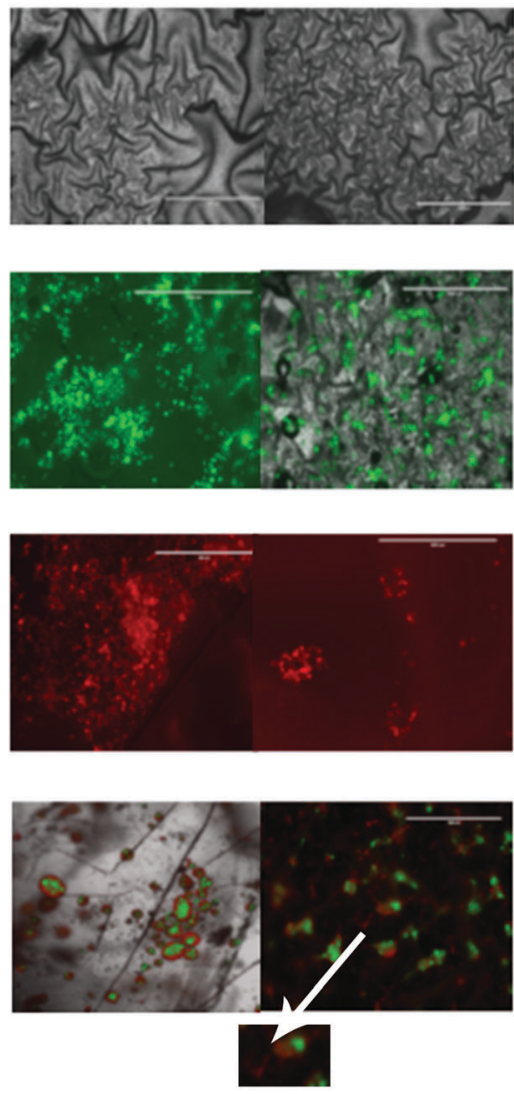

Fig. 4 Optical microscopy investigation of cell growth on the different hydrogel substrate types: dextran hydrogels with gelatin and silica particles, pullulan-amylose gels with and without gelatin and silica particles. (A) After swelling; (B) monoculture osteoblasts; (C) monoculture HUVECs; (D) coculture osteoblasts and HUVECs. Scale bars represent $200 \mu \mathrm{m}$.

topographic features of the gels and allow partial cell penetration into the film surface. The results indicate that dextran enhances the adhesion of the cells, whereas the amylose-pullulan mixture, although biocompatible, does not significantly support cell adhesion. Interestingly, in contrast to dextran gels, where we detected major differences in cell growth on gels with and without silica/gelatin addition, ${ }^{24}$ these differences were not seen on pullulanamylose gels. However, these differences imply various possible applications for the analyzed hydrogels: although dextran hydrogels show improved cell growth, pullulan-amylose gels might be advantageous as carrier systems for cytokines. This interesting perspective will be explored in follow-up studies.

Although previous studies investigated the biocompatibility of dextran-pullulan and amylose hydrogels, ${ }^{25,55}$ not much is known about the cell growth characteristics of various cell types on these hydrogels. Thebaud et al. ${ }^{56}$ analyzed endothelial cell growth on pullulan-dextran-fucoidan hydrogels, that were crosslinked chemically with sodium trimetaphosphate, and observed cell adhesion after 24 hours culture. However, they did not analyze cell growth over longer periods of time. This might explain the differences in our results as we focused on longer culture periods, where we only observed endothelial cell growth after addition of growth factors. To our knowledge, no studies assessing cell growth, especially over extended periods of time, have been performed on amylose or amylose-containing hydrogels.

\subsection{AlamarBlue assay}

Cell proliferation and viability of mono- and co-cultures on the different hydrogel substrates were quantified via the alamarBlue assay. Pure pullulan hydrogels did no swell substantially after incubation in PBS, whereas pure amylose hydrogels (data not shown) as well as the dextran hydrogels without $\mathrm{SiO}_{2} \mathrm{NPs}$ or gelatin exhibited only limited stability after swelling, and therefore no cells were seeded on these hydrogels. Dextran hydrogel composites with $\mathrm{SiO}_{2} \mathrm{NPs}$ and gelatin as well as hydrogels with different ratios of pullulan and amylose reinforced with $\mathrm{SiO}_{2} \mathrm{NPs}$ and supplemented with gelatin demonstrated a high stability after swelling. Therefore, hOB cells and HUVECs were seeded on these hydrogels after entrapment of BMP-2 and SDF-1, respectively.

As already observed in the microscopic studies above, the alamarBlue proliferation assay documented that hOBs grew well on the tested polysaccharide hydrogel composites even in the absence of growth factors BMP-2 and SDF-1. The growth could be slightly enhanced by approximately $10 \%$ on hydrogel composites 
with entrapped BMP-2. However, this enhancement was shown to be non-significant ( $p$-value $>0.05$ ). Comparing the overall growth behavior of hOBs on dextran hydrogels and pullulan-amylose gels, proliferation of hOBs was significantly higher $(p<0.05)$ on dextran gels, as indicated by the higher fluorescence intensity after four and five days (Fig. 5).

At the same time, HUVECs did not proliferate on any of the tested hydrogel composites without growth factors. This is in accordance with the microscopic observations above and previous literature reports, where the growth of HUVEC monocultures in three-dimensional models could not be established. ${ }^{37}$ However, our alamarBlue assay indicated that entrapment of SDF-1 in the hydrogel matrix substantially enhanced cell growth on all tested polysaccharide hydrogel composites $(p<0.05)$. Compared to pullulan-amylose hydrogels, the dextran hydrogels with cytokines showed a significantly enhanced proliferation $(p<0.05$, Fig. 5). The fact that addition of SDF- 1 significantly enhances proliferation of endothelial cells on the tested hydrogels indicates that the growth factor retains its functional activity

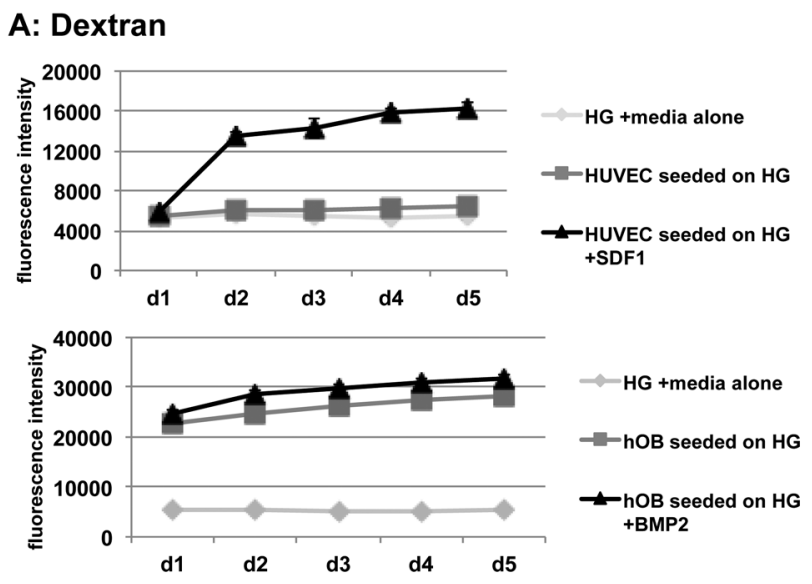

\section{B: Pullulan / Amylose}
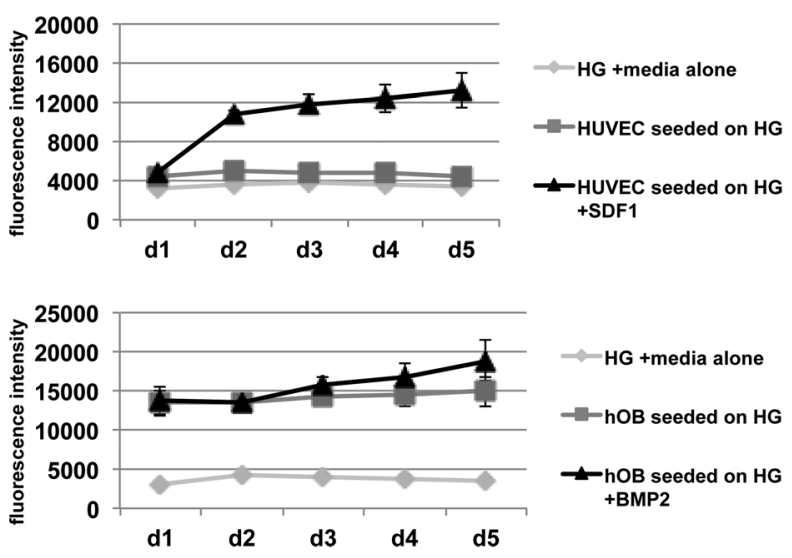

Fig. 5 Assessment of cell proliferation by alamarBlue assay of hOBs and HUVECs with and without hydrogel-associated cytokines SDF1 and BMP2, respectively, on the dextran $(A)$ and pullulan-amylose $(B)$ hydrogel systems (with the gain settings on the plate reader set to automatic adjustment.). after incorporation into the hydrogel composites, which has also been demonstrated for other types of hydrogels. ${ }^{15,57,58}$ This observation indicates various potential options for medical applications for these hydrogel composites and controlled cytokine release.

\subsection{Migration assays}

In order to determine the biologic function of entrapped SDF-1, particularly its chemotactic influence on endothelial cells, migration assays with cell culture inserts containing pores of $8 \mu \mathrm{m}$ was performed (for the experimental setup, see Fig. 6A). The migration of HUVECs from the chamber to the modified hydrogel was observed after addition of SDF-1 in all the gels used. This is in strong contrast to HUVECs cultured on hydrogel composites without SDF-1, where no migration activity of HUVECs was detected.

A standard curve was established correlating the fluorescence intensity with the cell number. Fig. 6 shows the calculated cell number of HUVECs, which migrated through the pores of the cell culture insert to the hydrogel substrate with and without SDF-1. On both hydrogel types, but without SDF-1 only approximately 40000 migrated HUVECs could be detected after six days of culture. In contrast, on both hydrogel types loaded with SDF-1 approximately 60000 cells could be detected already after two

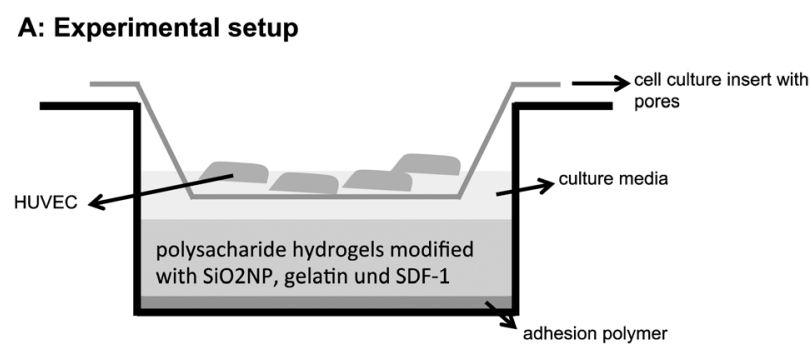

B: Dextran

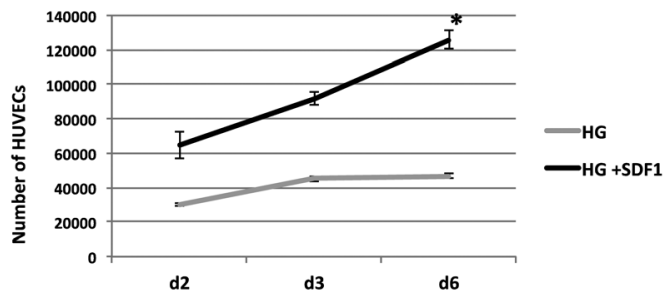

\section{C: Pullulan/Amylose}

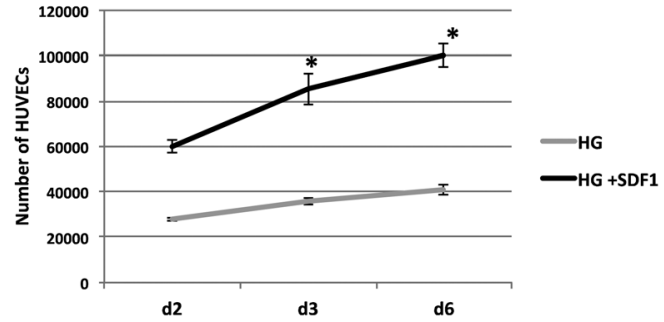

Fig. 6 Cell migration assay to test the influence of SD-1-modification on the dextran and pullulan-amylose hydrogels with HUVECs. (A) Experimental setup; (B) migration of HUVECs to dextran hydrogels with and without SDF1; (C) migration of HUVECs to pullulan-amylose hydrogels with and without SDF1. Asterisks indicate significant differences $(p<0.05)$. 
days of culture. After 6 days of culture, this number further increased to 120000 cells on dextran gels and 100000 cells on pullulan-amylose gels (Fig. 6, significance $p<0.05$ on day 6). In summary, the results of the migration and proliferation assays confirm the indication that SDF-1 retains its positive influence on proliferation and its chemotactic effect on endothelial cells after incorporation into the hydrogel matrix.

The results of the migration assays confirm the data obtained from the alamarBlue proliferation assay above by showing migration of HUVECs through the cell culture insert to the SDF-1-modified hydrogels. This behavior demonstrates the chemotactic characteristic of SDF-1 to endothelial cells even after incorporation into the hydrogels. Naderi-Meshkin ${ }^{59}$ demonstrated the chemotactic effect of SDF-1 on adipose tissue-derived stem cells (hASC) in injectable hydrogels and Prokoph et al. ${ }^{60,61}$ on circulating endothelial progenitor cells (EPC) in heparin-based hydrogels. The present findings demonstrate for the first time that incorporated SDF-1 retains its chemotactic effect on human umbilical endothelial cells in dextran-. and pullulan-amylose based hydrogels.

\subsection{Gene expression}

In order to demonstrate the influence of incorporated cytokines on gene regulation in the two employed cell types, analysis of specific marker expressions of the respective cell types was performed by real-time PCR. In the case of hOBs, the expression of Runt-related transcription factor 2 (Runx2, a transcription factor required for osteoblast differentiation), alkaline phosphatase (ALP, an early marker protein of osteoblast differentiation), osteopontin (OP, an important factor for biomineralization and bone remodeling) and osterix (SSP1, a transcription factor required for osteoblast differentiation) was significantly enhanced by a factor of 10-38 on BMP-2-modified hydrogels compared to cytokine-free gels $(p<0.05)$. In all four analyzed genes concerning osteoblast markers, the expression was more enhanced $(p<0.05)$ on dextran gels compared to pullulan-amylose gels (Fig. 7A).

The expression of the endothelial marker CD31, vonWillebrand-factor (vWF), and the VEGF-receptor KDR was significantly enhanced by a factor of 2-18 in HUVECs after SDF-1 modification on both gel types ( $p<0.05$, Fig. 7B). In the case of CD31, the expression was significantly enhanced on dextran gels compared to pullulan-amylose gels, whereas only non-significant differences between the two gel types were found concerning the vWF and KDR gene expression.

The PCR data again confirm the functional activity of entrapped and subsequently released growth factors and support the proliferation and migration assay results (Fig. 5 and 6).

In the case of osteoblast markers, the enhancement is more pronounced on dextran gels compared to amylose/pullulan gels, which is in accordance with the former results. Summarizing the enhancement of the expression of markers, especially ALP, Runx2 and SP7, and SP7 with an extremely high fold change of up to 30 indicated an immense is extremely high, indicating an immense effect of BMP2 on osteoblast viability and differentiation. Chen et al. ${ }^{62,63}$ and Dhivya et al. ${ }^{64}$ demonstrated an enhanced osteoblast marker expression on thermo-responsive hydrogels and hyaluronic acid- $g$-chitosan- $g$-poly( $N$-isopropylacrylamide) (HA-CPN) with fetal

\section{A: hOB}

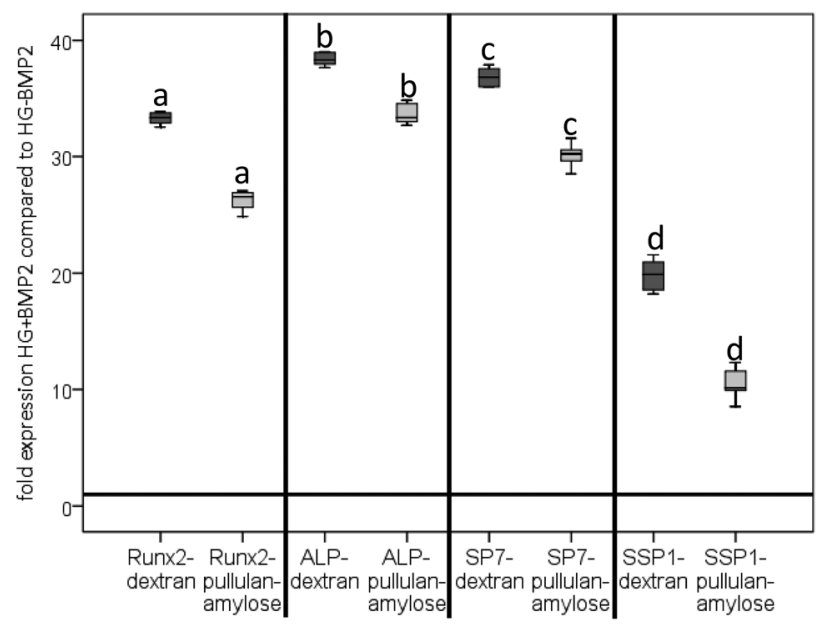

\section{B: HUVEC}

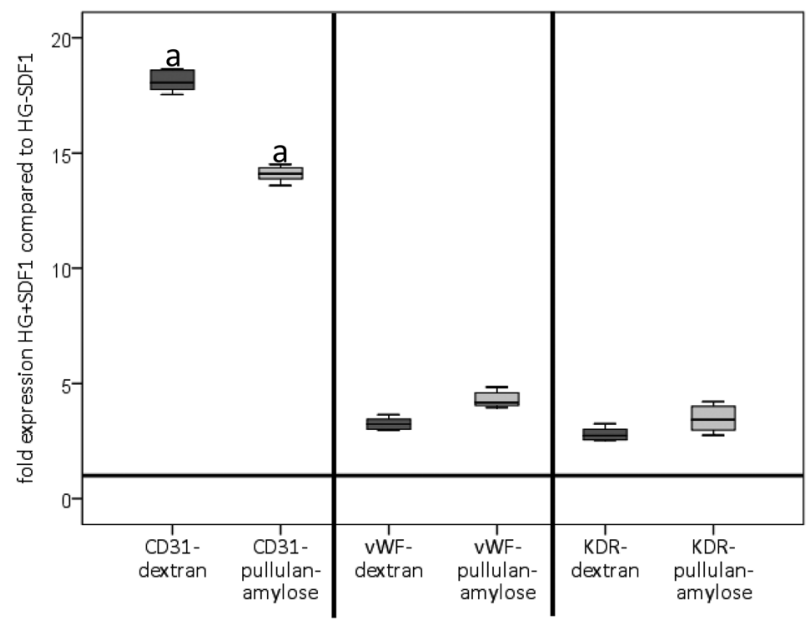

Fig. 7 Gene expression of osteoblast specific markers on hydrogels loaded with BMP-2 (A) and endothelial markers on hydrogels loaded with SDF-1 (B). Significant differences in the expression levels for a given marker on the different gel types are indicated by the same letters.

osteoblasts after a long culture period (3-4 weeks) and nanohydroxyapatite-chitosan hydrogels with mouse mesenchymal stem cells, respectively. They reported an up to 14 -fold enhanced expression of these markers; however, they employed hydrogels without growth factors. Rath et al. ${ }^{65}$ implanted hyaluronan hydrogels with BMP-2 or primary osteoblasts, but the although gene expression of osteoblastic markers was enhanced, no significant bone formation was observed. Kim et al. ${ }^{66}$ analyzed hyaluronic acid-based hydrogels loaded with BMP-2 and observed an enhanced marker expression (up to 30 fold) comparable to our new results. In our study, the enhancement of osteoblast marker expression was detected after BMP-2 loading on all tested hydrogels. Our results as well as the results described in the literature indicate that different hydrogels enhance marker expression in osteoblasts and this enhancement 
can be heightened by the addition of BMP-2. However, these effects have to be further analyzed, examined and confirmed in in vivo experiments.

To our knowledge, up to now no results exist for gene expression analyses concerning HUVECs on hydrogels with or without SDF-1. In our setup, the endothelial marker CD31 is more enhanced on the dextran gel, whereas the other two markers, vWF and KDR, appear marginally better on pullulan-amylose hydrogels. The enhancement of CD31 gene expression is more pronounced than the two other markers. As SDF-1 is an important contributor to neovascularization ${ }^{67}$ and CD31 is highly expressed on cells contributing to angiogenesis (reviewed in ref. 68), these results match well. As the results obtained from the viability assay as well as from the migration assays demonstrate better results for dextran gels compared to pullulan/amylose gels it is a logical consequence that CD31 expression is more enhanced on dextran gels than on pullulan/amylose gels. With regard to vWF and $\mathrm{KDR}$, their expression is marginally better on pullulan/amylose gels compared to dextran gels, yet these differences are not statistically significant. Their overall expression enhancement is much lower compared to CD31. This can be explained as these markers are typically expressed on endothelial cells but their expression is not as much correlated to angiogenesis as CD31. vWF, for instance, plays an important role in hemostasis rather than angiogenesis (reviewed by Yee et al., 2015 ${ }^{69}$ ).

We could clearly show that SDF-1 incorporated into polysaccharide hydrogels enhances proliferation, migration and endothelial marker expression, indicating the positive effect of SDF-1 on endothelial cells even when loaded into polysaccharide hydrogels.

We believe that these results will be of great interest and importance for applications where polysaccharide hydrogel systems are used as cell and/or drug carriers in bone tissue engineering.

\section{Conclusions}

In the present study, we have generated a range of different polysaccharide-based hydrogel composites, which possess all requirements demanded for a biomaterial. Dextran-based gels demonstrated the best cellular growth, differentiation and proliferation, whereas pullulan-amylose gels seem to have better mechanical properties, thus proposing different application areas for these two gel types. Dextran-based hydrogel composites might be more suitable for cellular-based tissue engineering, whereas pullulan-amylose hydrogel composites seem to be more promising as carrier systems, especially concerning endothelial enhancement by addition of SDF-1. The hydrogel composite materials developed in this study can further find applications in the modification of the existing materials approved by regulatory agencies for use in the human body. For example, the in vivo performance of titanium implants approved by the FDA (Food and Drug Administration) may be improved. We project that the results presented here and the platform developed in the present study will further aid in the development of novel and improved implants for bone repair applications.

\section{Acknowledgements}

The authors would like to acknowledge financial support through a stage I grant (Stufe I-Förderung) from the UNIVERSITÄTSMEDIZIN of the Johannes Gutenberg-Universität Mainz. Isabel Höfer acknowledges the Student Award of the County Olpe 2014. The authors also thank Annette Brunsen for providing data from her PhD thesis.

\section{References}

1 B. Johnstone, M. Alini, M. Cucchiarini, G. R. Dodge, D. Eglin, F. Guilak, H. Madry, A. Mata, R. L. Mauck, C. E. Semino and M. J. Stoddart, Eur. Cells Mater., 2013, 25, 248-267.

2 R. A. Kamel, J. F. Ong, E. Eriksson, J. P. Junker and E. J. Caterson, J. Am. Coll. Surg., 2013, 217, 533-555.

3 B. C. Karikkineth and W. H. Zimmermann, Curr. Pharm. Biotechnol., 2013, 14, 4-11.

4 D. Massai, G. Cerino, D. Gallo, F. Pennella, M. A. Deriu, A. Rodriguez, F. M. Montevecchi, C. Bignardi, A. Audenino and U. Morbiducci, J. Healthc. Eng., 2013, 4, 329-370.

5 H. Zhang, L. Zhou and W. Zhang, Tissue Eng., Part B, 2014, 20, 492-502.

6 B. D. Ratner, J. Cardiovasc. Transl. Res., 2011, 4, 523-527.

7 S. H. Chen, C. T. Tsao, C. H. Chang, Y. T. Lai, M. F. Wu, Z. W. Liu, C. N. Chuang, H. C. Chou, C. K. Wang and K. H. Hsieh, Macromol. Mater. Eng., 2013, 298, 429-438.

8 G. M. Sun, X. J. Zhang, Y. I. Shen, R. Sebastian, L. E. Dickinson, K. Fox-Talbot, M. Reinblatt, C. Steenbergen, J. W. Harmon and S. Gerecht, Proc. Natl. Acad. Sci. U. S. A., 2011, 108, 20976-20981.

9 D. F. Sweeney, Eye Contact Lens, 2013, 39, 53-60.

10 D. F. Sweeney, J. Stern, T. Naduvilath and B. A. Holden, Invest. Ophthalmol. Visual Sci., 2002, 43, U214.

11 J. M. Gonzalez-Meijome, A. C. da Silva, H. Neves, D. LopesFerreira, A. Queiros and J. Jorge, Contact Lens Anterio, 2013, 36, 86-92.

12 P. Matricardi, C. Di Meo, T. Coviello, W. E. Hennink and F. Alhaique, Adv. Drug Delivery Rev., 2013, 65, 1172-1187.

13 D. Seliktar, Science, 2012, 336, 1124-1128.

14 Amrita, A. Arora, P. Sharma and D. S. Katti, Carbohydr. Polym., 2015, 123, 180-189.

15 K. Minier, A. Toure, M. Fusellier, B. Fellah, B. Bouvy, P. Weiss and O. Gauthier, Vet. Comp. Orthop. Traumatol., 2014, 27, 411-421.

16 B. D. Walters and J. P. Stegemann, Acta Biomater., 2014, 10, 1488-1501.

17 N. I. Zur Nieden, C. C. Turgman, X. Lang, J. M. Larsen, J. Granelli, Y. J. Hwang and J. G. Lyubovitsky, ACS Appl. Mater. Interfaces, 2015, 7, 10599-10605.

18 S. L. Fenn and R. A. Oldinski, J. Biomed. Mater. Res., Part B, 2015, 7, 184-195.

19 S. Varghese and J. H. Elisseeff, Polymers for Regenerative Medicine, 2006, 95-144, DOI: 10.1007/12_072.

20 P. Bianco and P. G. Robey, Nature, 2001, 414, 118-121. 
21 D. Steiner, F. Lampert, G. B. Stark and G. Finkenzeller, J. Orthop. Res., 2012, 30, 1682-1689.

22 A. R. Shah, S. R. Shah, S. Oh, J. L. Ong, J. C. Wenke and C. M. Agrawal, Ann. Biomed. Eng., 2011, 39, 2501-2509.

23 A. Hofmann, U. Ritz, M. H. Hessmann, C. Schmid, A. Tresch, J. D. Rompe, A. Meurer and P. M. Rommens, Bone, 2008, 42, 894-906.

24 A. Brunsen, U. Ritz, A. Mateescu, I. Hofer, P. Frank, B. Menges, A. Hofmann, P. M. Rommens, W. Knoll and U. Jonas, J. Mater. Chem., 2012, 22, 19590-19604.

25 A. Abed, N. Assoul, M. Ba, S. M. Derkaoui, P. Portes, L. Louedec, P. Flaud, I. Bataille, D. Letourneur and A. Meddahi-Pelle, J. Biomed. Mater. Res., Part A, 2011, 96A, 535-542.

26 A. Autissier, D. Letourneur and C. Le Visage, J. Biomed. Mater. Res., Part A, 2007, 82, 336-342.

27 R. S. Singh, G. K. Saini and J. F. Kennedy, Carbohydr. Polym., 2008, 73, 515-531.

28 H. Li, J. Yang, X. Hu, J. Liang, Y. Fan and X. Zhang, J. Biomed. Mater. Res., Part A, 2011, 98, 31-39.

29 A. Lisman, B. Butruk, I. Wasiak and T. Ciach, J. Biomater. Appl., 2014, 28, 1386-1396.

30 J. A. Cadee, M. J. van Luyn, L. A. Brouwer, J. A. Plantinga, P. B. van Wachem, C. J. de Groot, W. den Otter and W. E. Hennink, J. Biomed. Mater. Res., 2000, 50, 397-404.

31 P. Xiao, S. Q. Shi and J. Nie, Polym. Adv. Technol., 2008, 19, 1305-1310.

32 L. L. Cheng, Y. Zhang and W. F. Shi, Chem. Res. Chin. Univ., 2011, 27, 145-149.

33 P. W. Beines, I. Klosterkamp, B. Menges, U. Jonas and W. Knoll, Langmuir, 2007, 23, 2231-2238.

34 J. Jia, M. Sarker, M. G. Steinmetz, R. Shukla and R. Rathore, J. Org. Chem., 2008, 73, 8867-8879.

35 C. R. van den Brom, I. Anac, R. F. Roskamp, M. Retsch, U. Jonas, B. Menges and J. A. Preece, J. Mater. Chem., 2010, 20, 4827-4839.

36 L. Zhang, E. M. Furst and K. L. Kiick, J. Controlled Release, 2006, 114, 130-142.

37 A. Hofmann, U. Ritz, S. Verrier, D. Eglin, M. Alini, S. Fuchs, C. J. Kirkpatrick and P. M. Rommens, Biomaterials, 2008, 29, 4217-4226.

38 C. Brendel, U. Muller-Kuller, S. Schultze-Strasser, S. Stein, L. Chen-Wichmann, A. Krattenmacher, H. Kunkel, A. Dillmann, M. N. Antoniou and M. Grez, Gene Ther., 2012, 19, 1018-1029.

39 X. Cai, L. Yang, L. M. Zhang and Q. Wu, Carbohydr. Res., 2010, 345, 922-928.

40 V. W. Wong, K. C. Rustad, M. G. Galvez, E. Neofytou, J. P. Glotzbach, M. Januszyk, M. R. Major, M. Sorkin, M. T. Longaker, J. Rajadas and G. C. Gurtner, Tissue Eng., Part A, 2011, 17, 631-644.

41 V. W. Wong, K. C. Rustad, J. P. Glotzbach, M. Sorkin, M. Inayathullah, M. R. Major, M. T. Longaker, J. Rajadas and G. C. Gurtner, Macromol. Biosci., 2011, 11, 1458-1466.

42 S. Li, Bioresour. Technol., 2010, 101, 2197-2202.

43 J. Kadokawa, Biomolecules, 2013, 3, 369-385.
44 J. Kadokawa, S. Nomura, D. Hatanaka and K. Yamamoto, Carbohydr. Polym., 2013, 98, 611-617.

45 R. K. Garg, R. C. Rennert, D. Duscher, M. Sorkin, R. Kosaraju, L. J. Auerbach, J. Lennon, M. T. Chung, K. Paik, J. Nimpf, J. Rajadas, M. T. Longaker and G. C. Gurtner, Stem Cells Transl. Med., 2014, 3, 1079-1089.

46 Y. Hashimoto, S. A. Mukai, S. Sawada, Y. Sasaki and K. Akiyoshi, Biomaterials, 2015, 37, 107-115.

47 J. C. Fricain, S. Schlaubitz, C. Le Visage, I. Arnault, S. M. Derkaoui, R. Siadous, S. Catros, C. Lalande, R. Bareille, M. Renard, T. Fabre, S. Cornet, M. Durand, A. Leonard, N. Sahraoui, D. Letourneur and J. Amedee, Biomaterials, 2013, 34, 2947-2959.

48 L. Choritz, M. Wegner, R. Forch, U. Jonas and H. Thieme, Ophthalmologe, 2013, 110, 714-721.

49 P. Chatakun, R. Nunez-Toldra, E. J. Diaz Lopez, C. Gil-Recio, E. Martinez-Sarra, F. Hernandez-Alfaro, E. Ferres-Padro, L. Giner-Tarrida and M. Atari, Cell. Mol. Life Sci., 2014, 71, 113-142.

50 T. T. Lau and D. A. Wang, Expert Opin. Biol. Ther., 2011, 11, 189-197.

51 Y. Kimura and Y. Tabata, J. Biomater. Sci., Polym. Ed., 2010, 21, 37-51.

52 P. Misra, D. Lebeche, H. Ly, M. Schwarzkopf, G. Diaz, R. J. Hajjar, A. D. Schecter and J. V. Frangioni, J. Nucl. Med., 2008, 49, 963-969.

53 A. R. Poynton and J. M. Lane, Spine, 2002, 27, S40-S48.

$54 \mathrm{~W}$. Zhu, O. Boachie-Adjei, B. A. Rawlins, B. Frenkel, A. L. Boskey, L. B. Ivashkiv and C. P. Blobel, J. Biol. Chem., 2007, 282, 18676-18685.

55 C. Desevaux, P. Dubreuil, V. Lenaerts and C. Girard, J. Biomed. Mater. Res., 2002, 63, 772-779.

56 N. B. Thebaud, D. Pierron, R. Bareille, C. Le Visage, D. Letourneur and L. Bordenave, J. Mater. Sci.: Mater. Med., 2007, 18, 339-345.

57 R. J. Seelbach, P. Fransen, D. Pulido, M. D’Este, F. Duttenhoefer, S. Sauerbier, T. M. Freiman, P. Niemeyer, F. Albericio, M. Alini, M. Royo, A. Mata and D. Eglin, Macromol. Biosci., 2015, 15, 1035-1044.

58 J. L. Holloway, H. Ma, R. Rai, K. D. Hankenson and J. A. Burdick, Macromol. Biosci., 2015, 15, 1218-1223.

59 H. Naderi-Meshkin, M. M. Matin, A. Heirani-Tabasi, M. Mirahmadi, M. Irfan-Maqsood, M. A. Edalatmanesh, M. Shahriyari, N. Ahmadiankia, N. S. Moussavi, H. R. Bidkhori and A. R. Bahrami, Cell Biol. Int., 2015, 40, 730-741.

60 L. Baumann, S. Prokoph, C. Gabriel, U. Freudenberg, C. Werner and A. G. Beck-Sickinger, J. Controlled Release, 2012, 162, 68-75.

61 S. Prokoph, E. Chavakis, K. R. Levental, A. Zieris, U. Freudenberg, S. Dimmeler and C. Werner, Biomaterials, 2012, 33, 4792-4800.

62 J. P. Chen, M. J. Tsai and H. T. Liao, Colloids Surf., B, 2013, 110, 120-129.

63 X. Chen and S. L. Thibeault, J. Tissue Eng. Regener. Med., 2013, 2013, 6228-6231. 
64 S. Dhivya, S. Saravanan, T. P. Sastry and N. Selvamurugan, J. Nanobiotechnol., 2015, 13, 40.

65 S. N. Rath, G. Pryymachuk, O. A. Bleiziffer, C. X. Lam, A. Arkudas, S. T. Ho, J. P. Beier, R. E. Horch, D. W. Hutmacher and U. Kneser, J. Mater. Sci.: Mater. Med., 2011, 22, 1279-1291.

66 J. Kim, Y. Park, G. Tae, K. B. Lee, C. M. Hwang, S. J. Hwang, I. S. Kim, I. Noh and K. Sun, J. Biomed. Mater. Res., Part A, 2009, 88, 967-975.
67 R. Lima e Silva, J. Shen, S. F. Hackett, S. Kachi, H. Akiyama, K. Kiuchi, K. Yokoi, M. C. Hatara, T. Lauer, S. Aslam, Y. Y. Gong, W. H. Xiao, N. H. Khu, C. Thut and P. A. Campochiaro, FASEB J., 2007, 21, 3219-3230.

68 S. Park, C. M. Sorenson and N. Sheibani, Clin. Sci., 2015, 129, 217-234.

69 A. Yee, A. N. Oleskie, A. M. Dosey, C. A. Kretz, R. D. Gildersleeve, S. Dutta, M. Su, D. Ginsburg and G. Skiniotis, Blood, 2015, 126, 939-942. 